\title{
Anaemia in the Premature Infant and Red Blood Cell Transfusion: New Approaches to an Age-Old Problem
}

Chad C. Andersen, $M_{B B S^{1,2, *}}$

Amy K. Keir, MBBS, $\mathrm{MPH}^{1,2}$

Haresh M. Kirpalani, $M D^{3}$

Michael J. Stark, MBChB, $P h D^{1,2}$

\author{
Address \\ ${ }^{*}, 1$ Department of Neonatal Medicine, Women's and Children's Hospital, Level 1, \\ Queen Victoria Building, 72 King William Rd, North Adelaide, South Australia \\ 5006, Australia \\ Email: chad.andersen@health.sa.gov.au \\ ${ }^{2}$ Robinson Research Institute, University of Adelaide, Adelaide, South Australia, \\ Australia \\ ${ }^{3}$ Neonatal Division, Department of Pediatrics, The Children's Hospital of Philadel- \\ phia, University of Pennsylvania, Philadelphia, PA, USA
}

Published online: 30 July 2015

(C) Springer International Publishing AG 2015

\section{This article is part of the Topical Collection on Neonatology}

Keywords Infant - Preterm · Anaemia - Blood transfusion - 0xygen consumption · Oxygen delivery

\section{Opinion statement}

Red blood cell (RBC) transfusion is a common intervention in very preterm infants with variable utilisation between centres and individual clinicians. This variation likely reflects uncertainty about who, when and how much to transfuse. Most RBC transfusions are given in small volumes as "top-up" for anaemia or cumulative phlebotomy loss. Whilst the newly born infant may have a low haemoglobin $(\mathrm{Hb})$ value, it is uncertain if this is of clinical or physiologic significance except at extreme values. Little attention has been given to the potentially favourable effect of RBC transfusion on oxygen kinetics, particularly in the interval after birth when the risk of hypoxic ischaemia is high. Later anaemia, at the time of likely $\mathrm{Hb}$ nadir, more typifies anaemia of prematurity. In this article, we will firstly review the conventional model of RBC transfusion based on haemoglobin $[\mathrm{Hb}]$ thresholds and secondly, we will propose an alternate, individualised, practice based on the oxygen physiology. This effectively reframes the potential role of RBC transfusion in the very preterm infant and demands a new generation of clinical trials. 


\section{Introduction}

Red blood cell (RBC) transfusion remains a common intervention particularly in very preterm infants. Recent data from the Canadian Neonatal Network $(\mathrm{CNN})$ indicates that over three quarters of infants born $<1000 \mathrm{~g}$ receive at least one $\mathrm{RBC}$ transfusion during their initial hospitalisation [1]. RBC transfusion utilisation varies between centre and individuals around the world. This is most likely due to the fact that there is no universally accepted haemoglobin $(\mathrm{Hb})$ transfusion threshold nor agreement on a working definition of anaemia of prematurity in the preterm infant [2-4]. This may explain the limited high-quality evidence available regarding the benefits and potential harms of RBC transfusion in this population [5].

Since the clinical indication of transfusion in cases of anaemic shock is not disputed, most attention has focused on RBC transfusion for anaemia of prematurity. This condition is defined by significant anaemia in the context of phlebotomy blood losses, lower erythropoietin (EPO) (hepatic versus renal) production and a limited bone marrow response [6]. It represents a pathologic extreme of physiologic anaemia in a high-risk population of preterm infants and is the commonest reason for transfusion in the nursery [7]. Outside of this indication, there is an emerging role for RBC transfusion following preterm birth as a result of its potential to favourably alter oxygen physiology thereby ameliorating hypoxic ischemic end organ (brain) injury [8]. In order to understand this possible indication, neonatal clinicians need to redefine the transfusion question in terms of oxygen physiology. In this article, we first review the conventional model of transfusion practice in the setting of anaemia of prematurity. We then propose an alternate model for RBC transfusion in the immediate neonatal period based on likely physiology. Such a frame shift will demand a new generation of clinical trials to test these hypotheses.

\section{Anaemia of prematurity}

Anaemia of prematurity is usually defined by a combination of non-specific clinical symptoms with anaemia determined by either haemoglobin concentration $[\mathrm{Hb}]$ and/or haematocrit $[9,10]$. A decline in circulating RBCs is observed in all newborns after the first $24 \mathrm{~h}$ of age. In the preterm newborn, this fall is exaggerated and more rapid, to a nadir at 4-6 weeks of age [7]. However, there is no evidence in human preterm infants of a $[\mathrm{Hb}]$ or haematocrit threshold that results in inadequate tissue oxygenation or critical anaemia hypoxaemia. This has prompted a search for other potential biomarkers of transfusion requirement in the preterm infant [11]. Whilst some neonatal transfusion guidelines include a combination of absolute reticulocyte count in conjunction with $[\mathrm{Hb}]$ and/or haematocrit, there is little evidence to support this practice $[11,12]$. Serum lactate has also been proposed $[13,14]$ but is of limited clinical use as plasma levels reflect both production and hepatic metabolism [15]. Most studies of possible transfusion biomarkers have compared responses before and after RBC transfusion. Yet without the use of a clear physiologic transfusion threshold, the clinical utility of this work is uncertain.

Strategies to minimise transfusion include avoiding anaemia by facilitating transfer of (fetal) blood from the placenta [16], reducing iatrogenic blood loss from phlebotomy and transfusing allogeneic (adult) RBCs. Enteral iron supplementation is also important and may change later haematologic measures of iron status but not early transfusion practice in preterm infants [17]. The use of exogenous EPO has also been considered; however, recently updated Cochrane reviews do not support its routine use, either early [18] or late [19] in the neonatal course. These reviews demonstrate no reduction in mortality rates 
and/or significant morbidities following EPO exposure, though it does result in a small reduction in the number of RBC transfusions. The problem is it may increase the risk of retinopathy. Darbepoetin, a synthetic form of EPO, may also have neuroprotective effects [20] though this requires further study [18].

\section{Conventional model of transfusion practice in preterm infants}

The conventional model of RBC transfusion includes a transfusion algorithm based on either [Hb] or haematocrit, modified by chronologic age and need for respiratory support $[3,4,6]$. This model of transfusion practice has been studied in randomised trials in preterm infants. Two trials [3, 4] dominate the transfusion landscape in preterm infants and are the foundation of current neonatal transfusion practice. Both are relatively small given the frequency of RBC transfusion in this high-risk population. The trials, described below, randomised infants to either a liberal or restrictive transfusion schedule based on $[\mathrm{Hb}]$ or haematocrit; however, the population and outcomes differed slightly. The Premature Infants in Need of Transfusion (PINT) trial [3] primarily measured a composite of mortality and clinical morbidities whereas the Iowa trial [4] measured transfusion exposure. The difference in primary outcome measurement is particularly important when these two trials are combined to determine the risk to benefit ratio of a liberal versus restrictive approach to transfusion.

The PINT trial randomised 451 newborns $<48$ h of age who were $<31$ weeks gestation and weighed $<1000 \mathrm{~g}$ at birth [3]. The trial compared two different transfusion algorithms (liberal versus restrictive) both based on chronologic age and the need for respiratory support. The trial algorithms were based on clinical practices and Canadian expert recommendations [21]. The trial showed no difference in composite outcome of hospital mortality or survival without bronchopulmonary dysplasia (BPD), vision threatening retinopathy of prematurity (ROP) or brain injury on head ultrasound between the two groups. The liberal and restrictive transfusion arms had a $[\mathrm{Hb}]$ difference of $11 \mathrm{~g} / \mathrm{L}$ from the end of the second week [22]. Fewer newborns in the restrictive arm received any RBC transfusion ( 89 versus $95 \%$ restrictive versus liberal). There was no difference in $[\mathrm{Hb}]$ between allocated groups at hospital discharge though the liberal group had higher ferritin. At a two-year follow-up, there was a small, non-significant increase in the composite outcome of death or impairment (cerebral palsy, cognitive delay of 2SD below the mean (Bayley Scales of Infant Development), hearing loss or blindness) in the restrictive transfusion group (45.2 versus $38.5 \%$ restrictive versus liberal OR 1.45, Confidence Interval (CI) $0.94,2.21)$ [23]. A post hoc analysis of mild cognitive delay, defined as Mental Developmental Index less than or equal to 1SD below the mean, suggested a reduction favouring the liberal transfusion group.

The Iowa trial [4] randomised 100 newborns between 500 and $1300 \mathrm{~g}$ birth weight. Using locally chosen transfusion algorithms based on haematocrit thresholds that varied by the need for respiratory support, this trial reported a difference in the primary outcome of number of transfusions favouring fewer transfusions in the restrictive group. However, secondary outcomes of inhospital survival, ROP, BPD, time in supplemental oxygen or growth were not 
different. More infants in the restrictive group developed brain injury on head ultrasound though only half of the study cohort had a late 42-day scan $(n=52)$ [4]. A later brain MRI follow-up study of trial participants versus control infants suffered from marked attrition bias [24].

\section{Current RCT-based recommendations}

A Cochrane Review pooled available studies to recommended [Hb] thresholds for transfusion in the preterm neonate [25]. Although this review concluded that there was no clear benefit to the use of liberal versus restrictive [Hb] thresholds in very low birth weight neonates, the number of studies with longer term follow-up data was limited.

The risk versus benefit approach can be interpreted to derive two different hypotheses based on the same information. It may be argued that a restrictive transfusion practice is preferable, as more very preterm infants avoid transfusion without a worse outcome [26]. An alternate interpretation may be that a liberal transfusion practice is better for the possibility of a post hoc advantage in cognition [23]. Additional large trials using similar methodology are currently recruiting $[27,28]$. These studies, in combination with the two aforementioned trials may resolve some of the uncertainty particularly about the effect of transfusion thresholds on longer-term neurodevelopmental outcome.

\section{Transfusion safety}

\section{Can oxygen physiology rationalise early transfusion in preterm infants?}

There is uncertainty about the risks of RBC transfusion in very preterm newborns. Several uniquely neonatal adverse associations have been demonstrated in epidemiological studies [29]. These include death [30], necrotising enterocolitis (NEC) [26, 31], intraventricular haemorrhage (IVH) [32, 33], retinopathy of prematurity (ROP) [34] and chronic lung disease (CLD) [35]. It is important to note however, that these observational studies using case control or retrospective cohort methodology report risk ratios for NEC following exposure to RBC transfusion that far exceed those demonstrated in randomised trials. Given the substantial differences in reported rates of outcomes between randomised and observational studies, large-scale, multi-centre collaborations are required to confirm or refute these possible relationships [36] using standardised definitions of transfusion adverse events.

Conventional RBC transfusion practice using defined [Hb] thresholds is easy to understand and apply to clinical situations. However, this practice may oversimplify oxygen physiology as $\mathrm{Hb}$ is a continuous variable. It is unlikely that there is a single [Hb] threshold that results in anaemic hypoxia in any two 
infants at any particular time, as each will have different oxygen delivery and consumption conditions. In order to demonstrate this, we describe two hypothetical scenarios (Table 1) based on [Hb] levels. The first scenario shows newborns with different $[\mathrm{Hb}]$ but similar oxygen delivery values, whereas the second scenario shows newborns with similar $[\mathrm{Hb}]$ but quite different oxygen delivery. This table highlights the complexity of oxygen physiology and the simplicity of transfusion decision making on the basis of $[\mathrm{Hb}]$ alone.

Adult allogeneic RBC transfusion improves oxygen carrying capacity by increasing $[\mathrm{Hb}]$, which alters cardiac preload, and in addition results in a rightward shift in the haemoglobin-oxygen dissociation curve. These effects all favour improved systemic oxygen delivery to the end organs. However, if the primary reason for $\mathrm{RBC}$ transfusion is to improve oxygenation, then other variables of oxygen physiology apart from $\mathrm{Hb}$ alone must be considered. These other variables are primarily oxygen saturation, cardiac output and oxygen consumption. In simple terms, an optimal [Hb] could be derived from oxygen physiology. This $[\mathrm{Hb}]$ might then be used as the transfusion threshold.

Oxygen kinetics is a broad term used to describe the relationship between oxygen delivery, extraction and consumption. At rest, there is an excess of delivery over consumption. As oxygen delivery falls, oxygen extraction, that is the proportion of oxygen unloaded from haemoglobin, increases to maintain consumption. A further decline in oxygen delivery, below a critical threshold, results in an anaerobic debt and accumulation of lactate.

It was Barcroft who originally defined the key determinants of oxygen delivery, namely blood flow, [Hb] and Hb-oxygen saturation. From this, he postulated three hypoxaemic states: stagnant hypoxia (poor blood flow), anaemic hypoxia (low [Hb]) and hypoxic hypoxia (low oxygen tension) [37]. Of all the determinants of optimal oxygen delivery, blood flow is the most critical $[38,39]$. For this reason, attention has focused on improving systemic perfusion in very preterm infants, particularly in the setting of low systemic blood flow [40]. Unfortunately, these strategies have not reduced significant morbidities following preterm birth [41]. This may be the result of a narrow focus on a single element of oxygen physiology in this population.

\section{RBC transfusion and oxygen extraction}

Oxygen consumption is variable in preterm infants [42] with studies showing that body temperature and pulmonary work of breathing [43] alter systemic oxygen consumption. More recently, near-infrared spectroscopy (NIRS) has been combined with reversed Fick techniques [44] to determine tissue oxygen delivery, consumption and fractional tissue oxygen extraction (FTOE) [45]. Studies show that both cerebral and peripheral FTOE are elevated in infants with symptomatic anaemia [46] and fall following RBC transfusion [47, 48]. This observation has led some to propose that FTOE be used as a trigger for transfusion [49]. To date, however, studies have principally focused on later anaemia thus ignoring the potential early benefit.

Whilst oxygen consumption determines FTOE, it is the adequacy of oxygen delivery that defines clinical success or failure [42]. Adequate oxygen delivery results in relatively normoxic tissue conditions, whereas suboptimal oxygen 
Table 1. Oxygen delivery calculated from [Hb], Hb-oxygen saturation and cardiac output values in two hypothetical clinical scenarios

\begin{tabular}{|c|c|c|c|c|c|c|}
\hline Scenario & & $\begin{array}{l}\text { Haemoglobin } \\
(\mathrm{g} / \mathrm{dL})\end{array}$ & $\begin{array}{l}\text { Oxygen } \\
\text { saturation } \\
(\%)\end{array}$ & $\begin{array}{l}\text { Arterial oxygen } \\
\text { content }\left(\mathrm{CaO}_{2}\right) \\
\text { (mL } \mathrm{O}_{2} / \mathrm{dL} \text { blood) }\end{array}$ & $\begin{array}{l}\text { Cardiac } \\
\text { output } \\
(\mathrm{mL} / \mathrm{kg} / \mathrm{min})\end{array}$ & $\begin{array}{l}\text { Oxygen delivery } \\
\left(\mathrm{DO}_{2}{ }^{\mathrm{a}}\right) \\
(\mathrm{mL} / \mathrm{kg} / \mathrm{min})\end{array}$ \\
\hline Scenario A & Newborn 1 & 10.5 & 98 & 14.3 & 200 & 28.6 \\
\hline $\begin{array}{l}\text { Different }[\mathrm{Hb}]: \\
\text { similar oxygen } \\
\text { delivery }\end{array}$ & Newborn 2 & 16 & 85 & 18.9 & 150 & 28 \\
\hline Scenario B & Newborn 3 & 13.5 & 98 & 18.4 & 250 & 46 \\
\hline $\begin{array}{l}\text { Similar }[\mathrm{Hb}] \text { : } \\
\text { different oxygen } \\
\text { delivery }\end{array}$ & Newborn 4 & 13.5 & 91 & 17.1 & 150 & 25.6 \\
\hline
\end{tabular}

delivery leads to hypoxia and possible hypoxic ischaemic (brain) injury. Failed compensation may result from either inadequate oxygen delivery or elevated oxygen consumption or a mixture of both. If this is identified in a timely manner, RBC transfusion might favourably alter the relationship between oxygen delivery and consumption, thereby reducing the risk of relative cerebral anaemic hypoxia.

\section{How should we reframe the transfusion debate in preterm infants?}

There are two broad transfusion situations in preterm newborns with quite different oxygen physiology. The first relates to avoiding early anaemic hypoxia in the first days of life. This is typically the time of early lung disease, low systemic blood flow [40] and a haemodynamically significant patent ductus arteriosis. The second relates to correction of anaemia in a convalescent preterm newborn with variable reticulocytosis and chronic pulmonary lung disease requiring supplemental oxygen. We suggest that it is this later anaemia that is more characteristic of anaemia of prematurity.

\section{How can anaemic hypoxia immediately after birth be avoided?}

Two potential approaches can be navigated with one based on predicted physiology and the second alternate strategy determined by the actual physiology. Neither is proven, and both require pragmatic randomised trials before implementation.

(i) An approach using predicted physiology

In this approach, the quantity of oxygen carried in the blood stream is calculated from the measurement of both $[\mathrm{Hb}]$ and $\mathrm{Hb}$-oxygen saturation and used as a transfusion threshold. Arterial oxygen content $\left(\mathrm{CaO}_{2}\right)$ is calculated from $[\mathrm{Hb}]$ and $\mathrm{Hb}-$ oxygen saturation according to the equation 
$\mathrm{CaO}_{2}=\left\{\left([\mathrm{Hb}] \cdot \mathrm{SaO}_{2} \cdot 1.39\right)+\left(p \mathrm{aO}_{2} \cdot 0.003\right)\right\}$. It is a summary of the amount of oxygen carried by the blood. For example, an infant with a [Hb] of $115 \mathrm{~g} / \mathrm{L}$ who is well saturated $(96 \%)$ has a $\mathrm{CaO}_{2}$ of approximately $15 \mathrm{~mL}$ of oxygen per $100 \mathrm{~mL}$ of blood $\left(15 \mathrm{~mL} \mathrm{O}_{2} / \mathrm{dL}\right)$. Although measurement of $\mathrm{CaO}_{2}$ appears cumbersome, it is often calculated in each specimen by blood gas analysis machines with clinical ranges determined by the boundaries of both [Hb] and $\mathrm{Hb}$-oxygen saturation. It can be easily combined with contemporaneous measurement of blood flow, performed in many intensive care nurseries. But what $\mathrm{CaO}_{2}$ value should be targeted in a newly born preterm infant? This target or threshold level could be derived from the highest oxygen consumption values in a population of healthy very preterm newborns. This value would account for both postnatal age and illness severity, similarly to conventional transfusion thresholds.

Oxygen consumption literature in premature infants is difficult to interpret because of the use of varying methodologies. Whereas indirect calorimetry measures total body oxygen consumption, reverse Fick techniques exclude pulmonary oxygen consumption leading to a systematic bias in results [44]. We therefore measured cerebral oxygen consumption using the reverse Fick techniques in a population of 50 consecutive, very preterm newborns less than 30 weeks gestational age who did not have a brain injury on cranial ultrasound. Internal carotid blood flow (measured by Doppler) was used as a surrogate for cerebral blood flow. Arterial (measured by co-oximetry) and venous oxygen content (measured by NIRS) allowed calculation of the arteriovenous AV content difference. In our cohort, oxygen consumption increased from mean (SD) 4.3 (2.5) $\mathrm{mL} / \mathrm{kg} / \mathrm{min}$ in the first $24 \mathrm{~h}$, to 4.7 (2.6) $\mathrm{mL} / \mathrm{kg} / \mathrm{min}$ and 5.4 (3.6) $\mathrm{mL} / \mathrm{kg} / \mathrm{min}$ by 48 and $72 \mathrm{~h}$, respectively [50].

If we used a desirable cerebral oxygen consumption target of 2 standard deviations greater than the mean, $95 \%$ of our cohort would have avoided critical brain hypoxaemia. We have used this definition to derive an oxygen consumption target of $9.8 \mathrm{~mL} / \mathrm{kg} / \mathrm{min}$ in the first $24 \mathrm{~h}$ of life. $\mathrm{A} \mathrm{CaO}_{2}$ threshold level of $18 \mathrm{~mL} \mathrm{O}_{2} / \mathrm{dL}$ would provide enough oxygen to meet this a priori oxygen consumption target value. This would permit cerebral normoxic conditions even in the presence of low systemic blood flow (right ventricular output approximately $150 \mathrm{~mL} / \mathrm{kg} / \mathrm{min}$ ). This $\mathrm{CaO}_{2}$ value corresponds to a [Hb] of approximately $152 \mathrm{~g} / \mathrm{L}$, assuming that desired $\mathrm{SpO}_{2}$ is $85 \%$ or $136 \mathrm{~g} / \mathrm{L}$ if $\mathrm{SpO}_{2}$ is $95 \%$. Clearly, the target could be altered further with expected improvement in systemic blood flow.

(ii) An approach using actual physiology

In this approach, contemporaneous measurement of either oxygen extraction or a surrogate for tissue oxygen saturation could be used to target RBC transfusion in very preterm newborns. This would be particularly useful in the transitional interval after birth when oxygen physiology changes rapidly and the risk of acquired brain injury is the highest $[51,52]$. We, and others, have demonstrated that injury during this time is typically characterised by elevated cerebral FTOE $[50,53]$.

Before applying this approach, we require an understanding of the measured outcome and normal ranges in very preterm newborns. Firstly, oxygen extraction and tissue oxygenation index (TOI) are not interchangeable. Oxygen extraction is the proportion of oxygen unloaded from haemoglobin following 
blood passage through the tissues. Mathematically, it is a ratio of arterial and venous oxygen content. In contrast with TOI, extraction incorporates arterial oxygen saturation thereby changing slightly with different oxygen saturation targets (85-89\% versus $91-95 \%$ for example). Tissue oxygenation index is used in the oxygen extraction calculation. Often, it is measured by NIRS and used as a surrogate for venous oxygen saturation. However, it is not the same. The technology used by NIRS is similar to that used for oximetry, except that NIRS measures oxygenated $\mathrm{Hb}$ in the tissue whereas oximetry measures oxygenated $\mathrm{Hb}$ in the pulsatile blood vessel. As such, the TOI may vary as a result of changes in the venous: arterial blood compartment ratio in the measured tissue. This might occur, for example, with low systemic blood flow or with change in position. Reference ranges in term, near term and preterm newborns have been described by a number of researchers $[54,55]$. Hyttel-Sorensen and colleagues developed a treatment algorithm (SafeBoosC), based on cerebral tissue oxygen saturation, which was then applied in a randomised trial to show an improvement in stability of cerebral oxygenation [56]. This group defined the normal range for cerebral oxygen saturation as $55-85 \%$ based on the $95 \%$ CI in 493 infants $<32$ weeks in the first 3 days of life.

Transfusion with allogeneic adult RBCs can alter cardiac preload condition and oxygen-carrying capacity and lead to a rightward shift in the Hb-oxygen dissociation curve. All of these factors are advantageous to the preterm infant. In a non-randomised trial [57], we found that allogeneic RBC transfusion favourably altered oxygen kinetics but only in very preterm infants with high extraction. Given that extraction is inversely related to oxygen delivery, it is plausible that newborns operating with low extraction had adequate oxygen delivery and for this reason, did not benefit from RBC transfusion. In the SafeBoosC phase II trial, transfusion was considered at tissue oxygen saturation levels of less than $55 \%$. This corresponds to an extraction value of 0.42 if $\mathrm{SpO}_{2}$ is $95 \%$ or 0.35 if $\mathrm{SpO}_{2}$ is $85 \%$.

A randomised clinical trial based on contemporaneous physiology could be designed in a manner similar to that of Hyttel-Sorensen et al. with cerebral tissue oxygenation or oxygen extraction used as the trigger for RBC transfusion and with a control arm derived from a recent trial of conventional transfusion practice. The trial population should include preterm newborns at risk of the consequences of either inadequate and/or excessive oxygen exposure.

We recognise that a physiologic strategy for targeting oxygen delivery in premature infants has potential pitfalls. The most appropriate oxygen consumption target in very premature infants is not precisely known, and, like many measurements, there is significant variation or biological noise. The use of arterial oxygen content requires both invasive arterial access and consideration of oxygen saturation stability at the time of measurement. Cerebral oxygen kinetics might reflect the dynamic physiology for each newborn; however, this requires NIRS technology, which at present, is expensive, cumbersome, involves considerable training and is subject to inter-rater differences. newborn is hard to precisely quantify. The Hb nadir may be apparent from reticulocytosis. In addition, the infant may have rapid somatic 
growth and chronic pulmonary lung disease requiring supplemental oxygen with altered $\mathrm{Hb}$-oxygen affinity in keeping with advancing maturity. The transfusion threshold in this group of preterm infants is best determined in a conventional transfusion paradigm. The lowest studied [Hb] threshold in all randomised transfusion trials in preterm infants is similar, being between 70 and $75 \mathrm{~g} / \mathrm{L}$. Until there is further evidence, this likely represents the current best approach to the treatment of later anaemia in very preterm infants.

\section{Conclusion}

Red blood cell transfusion is a common intervention in very preterm infants with variability in decisions amongst clinicians about who, when and how much to transfuse. Anaemia of prematurity is an umbrella term used to describe the transfusion practice in preterm neonates. The approach to transfusion in the first days of life requires a new paradigm with a transfusion trigger based on optimisation of oxygen kinetics. Later anaemia, at the time of $\mathrm{Hb}$ nadir, might be best guided by $[\mathrm{Hb}]$ transfusion thresholds based on previous and contemporaneous clinical trials. In future research, we should separate these two transfusion situations to identify the best model of transfusion practice for preterm neonates.

\section{Compliance with Ethics Guidelines}

\section{Conflict of Interest}

The authors declare that they have no conflict of interest.

\section{Human and Animal Rights and Informed Consent}

This article does not contain any new studies involving human or animal subjects.

\section{References and Recommended Reading}

1. Keir AK, Yang J, Harrison A, Pelausa E, Shah PS, on Behalf of the Canadian Neonatal N. Temporal changes in blood product usage in preterm neonates born at less than 30 weeks' gestation in Canada. Transfusion. 2015.

2. Strauss RG. Practical issues in neonatal transfusion practice. Am J Clin Pathol. 1997;107:S57-63.

3. Kirpalani H, Whyte RK, Andersen C, Asztalos EV, Heddle N, Blajchman MA, et al. The Premature Infants in Need of Transfusion (PINT) study: a randomized, controlled trial of a restrictive (low) versus liberal (high) transfusion threshold for extremely low birth weight infants. J Pediatr. 2006;149(3):301-7.

4. Bell EF, Strauss RG, Widness JA, Mahoney LT, Mock DM, Seward VJ, et al. Randomized trial of liberal versus restrictive guidelines for red blood cell transfusion in preterm infants. Pediatrics. 2005;115(6):1685-91.

5. Guillen U, Cummings JJ, Bell EF, Hosono S, Frantz AR, Maier RF, et al. International survey of transfusion practices for extremely premature infants. Semin Perinatol. 2012;36(4):244-7.

6. Strauss RG. Anaemia of prematurity: pathophysiology and treatment. Blood Rev. 2010;24(6):221-5.

7. Wardrop CA, Holland BM, Veale KE, Jones JG, Gray OP. Nonphysiological anaemia of prematurity. Arch Dis Child. 1978;53(11):855-60.

8. Andersen CC, Stark MJ. Haemoglobin transfusion threshold in very preterm newborns: a theoretical 
framework derived from prevailing oxygen physiology. Med Hypotheses. 2012;78(1):71-4.

9. Gibson BE, Todd A, Roberts I, Pamphilon D, Rodeck C, Bolton-Maggs $\mathrm{P}$, et al. Transfusion guidelines for neonates and older children. Br J Haematol. 2004;124(4):433-53.

10. Miller Y, Bachowski G, Benjamin R. Practice guidelines for blood transfusion. 2nd ed: Americn Red Cross. 2007.

11. Banerjee J, Aladangady N. Biomarkers to decide red blood cell transfusion in newborn infants. Transfusion. 2014;54(10):2574-82.

12. Kasat K, Hendricks-Munoz KD, Mally PV. Neonatal red blood cell transfusions: searching for better guidelines. Blood transfusion. Trasfusione del sangue.

2011;9(1):86-94.

13. Moller JC, Schwarz U, Schaible TF, Artlich A, Tegtmeyer FK, Gortner L. Do cardiac output and serum lactate levels indicate blood transfusion requirements in anemia of prematurity? Intensive Care Med. 1996;22(5):472-6.

14. Takahashi D, Matsui M, Shigematsu R, Sato T, Miyaji R, Sakai $M$, et al. Effect of transfusion on the venous blood lactate level in very low-birthweight infants. Pediatr Int : Off J Jpn Pediatr Soc. 2009;51(3):321-5.

15. Duke T. Dysoxia and lactate. Arch Dis Child. 1999;81(4):343-50.

16. Rabe H, Diaz-Rossello JL, Duley L, Dowswell T. Effect of timing of umbilical cord clamping and other strategies to influence placental transfusion at preterm birth on maternal and infant outcomes. Cochrane Database Syst Rev. 2012;8:CD003248.

17. Long H, Yi JM, Hu PL, Li ZB, Qiu WY, Wang F, et al. Benefits of iron supplementation for low birth weight infants: a systematic review. BMC Pediatr. 2012;12:99.

18. Ohlsson A, Aher SM. Early erythropoietin for preventing red blood cell transfusion in preterm and/or low birth weight infants. Cochrane Database Syst Rev. 2014;4:CD004863.

19. Aher SM, Ohlsson A. Late erythropoietin for preventing red blood cell transfusion in preterm and/or low birth weight infants. Cochrane Database Syst Rev. 2014;4:CD004868.

20. Messier AM, Ohls RK. Neuroprotective effects of erythropoiesis-stimulating agents in term and preterm neonates. Curr Opin Pediatr. 2014;26(2):139-45.

21. Fetus and Newborn Committee CPS. Guidelines for transfusion of erythrocytes to neonates and premature infants. Can Med Assoc J. 1992;147:1781-92.

22. Whyte RK, Jefferies AL. Canadian Paediatric Society F, Newborn C. Red blood cell transfusion in newborn infants. Paediatr Child Health. 2014;19(4):213-22.

23. Whyte RK, Kirpalani H, Asztalos EV, Andersen C, Blajchman M, Heddle N, et al. Neurodevelopmental outcome of extremely low birth weight infants randomly assigned to restrictive or liberal hemoglobin thresholds for blood transfusion. Pediatrics. 2009;123(1):207-13.
24. Nopoulos PC, Conrad AL, Bell EF, Strauss RG, Widness JA, Magnotta VA, et al. Long-term outcome of brain structure in premature infants: effects of liberal vs restricted red blood cell transfusions. Arch Pediatr Adolesc Med. 2011;165(5):443-50.

25. Whyte R, Kirpalani H. Low versus high haemoglobin concentration threshold for blood transfusion for preventing morbidity and mortality in very low birth weight infants. Cochrane Database Syst Rev. 2011;11:CD000512.

26. Mohamed A, Shah PS. Transfusion associated necrotizing enterocolitis: a meta-analysis of observational data. Pediatrics. 2012;129(3):529-40.

27. Investigators E. The 'Effects of Transfusion Thresholds on Neurocognitive Outcome of Extremely Low BirthWeight Infants (ETTNO)' Study: Background, Aims, and Study Protocol. Neonatology. 2012;101(4):301-5. 28. ClinicalTrials.gov. Transfusion of Prematures. 2014.

29. Venkatesh V, Khan R, Curley A, Hopewell S, Doree C, Stanworth S. The safety and efficacy of red cell transfusions in neonates: a systematic review of randomized controlled trials. Br J Haematol. 2012;158(3):370-85.

30. Dos Santos AM, Guinsburg R, de Almeida MF, Procianoy RS, Leone CR, Marba ST, et al. Red blood cell transfusions are independently associated with intrahospital mortality in very low birth weight preterm infants. J Pediatr. 2011;159(3):371-76 e1-3.

31. Kirpalani H, Zupancic JA. Do transfusions cause necrotizing enterocolitis? The complementary role of randomized trials and observational studies. Semin Perinatol. 2012;36(4):269-76.

32. Baer VL, Lambert DK, Henry E, Snow GL, Butler A, Christensen RD. Among very-low-birthweight neonates is red blood cell transfusion an independent risk factor for subsequently developing a severe intraventricular hemorrhage? Transfusion. 2011;51(6):1170-8.

33. Christensen RD. Associations between "early" red blood cell transfusion and severe intraventricular hemorrhage, and between "late" red blood cell transfusion and necrotizing enterocolitis. Semin Perinatol. 2012;36(4):283-9.

34. Giannantonio C, Papacci P, Cota F, Vento G, Tesfagabir $M G$, Purcaro V, et al. Analysis of risk factors for progression to treatment-requiring ROP in a single neonatal intensive care unit: is the exposure time relevant? J Matern Fetal Neonatal. 2012;25(5):471-7.

35. Cooke RW, Drury JA, Yoxall CW, James C. Blood transfusion and chronic lung disease in preterm infants. Eur J Pediatr. 1997;156(1):47-50.

36. Kirpalani H, Whyte R. Truths, associations, and hypotheses. J Pediatr. 2011;159(3):359-61.

37. Barcroft J. Physiological effects of insufficient oxygen supply. Nature. 1920;106(2656):125-9.

38. Heusser F, Fahey JT, Lister G. Effect of hemoglobin concentration on critical cardiac output and oxygen transport. Am J Physiol. 1989;256(2 Pt 2):H527-32.

39. Cain SM. Oxygen delivery and uptake in dogs during anemic and hypoxic hypoxia. J Appl Physiol Respir Environ Exerc Physiol. 1977;42(2):228-34. 
40. Kluckow M, Evans N. Superior vena cava flow in newborn infants: a novel marker of systemic blood flow. Arch Dis Child Fetal Neonatal Ed. 2000;82(3):F182-7.

41. Osborn DA, Evans N, Kluckow M, Bowen JR, Rieger I. Low superior vena cava flow and effect of inotropes on neurodevelopment to 3 years in preterm infants. Pediatrics. 2007;120(2):372-80.

42. Kissack CM, Garr R, Wardle SP, Weindling AM. Cerebral fractional oxygen extraction is inversely correlated with oxygen delivery in the sick, newborn, preterm infant. J Cereb Blood Flow Metab : Off J Int Soc Cereb Blood Flow Metab. 2005;25(5):545-53.

43. Weinstein MR, Oh W. Oxygen consumption in infants with bronchopulmonary dysplasia. J Pediatr. 1981;99(6):958-61.

44. Nunn JF. Applied respiratory physiology. 3rd ed. London: Butterworths; 1987.

45. Murkin JM, Arango M. Near-infrared spectroscopy as an index of brain and tissue oxygenation. Br J Anaesth. 2009;103 Suppl 1:i3-i13.

46. Wardle SP, Drury J, Garr R, Weindling AM. Effect of blood transfusion on lipid peroxidation in preterm infants. Arch Dis Child Fetal Neonatal Ed. 2002;86(1).

47. van Hoften JC, Verhagen EA, Keating P, ter Horst HJ, Bos AF. Cerebral tissue oxygen saturation and extraction in preterm infants before and after blood transfusion. Arch Dis Child Fetal Neonatal Ed. 2010;95(5):F352-8.

48. Dani C, Pratesi S, Fontanelli G, Barp J, Bertini G. Blood transfusions increase cerebral, splanchnic, and renal oxygenation in anemic preterm infants. Transfusion. 2010;50(6):1220-6.

49. Wardle SP, Garr R, Yoxall CW, Weindling AM. A pilot randomised controlled trial of peripheral fractional oxygen extraction to guide blood transfusions in preterm infants. Arch Dis Child Fetal Neonatal Ed. 2002;86(1):F22-7.

50. Balegar KK, Stark MJ, Briggs N, Andersen CC. Early cerebral oxygen extraction and the risk of death or sonographic brain injury in very preterm infants. J Pediatr. 2014;164(3):475-480 e1.

51. Greisen G, Borch K. White matter injury in the preterm neonate: the role of perfusion. Dev Neurosci. 2001;23(3):209-12.

52. Altman DI, Perlman JM, Volpe JJ, Powers WJ. Cerebral oxygen metabolism in newborns. Pediatrics. 1993;92(1):99-104.

53. Verhagen EA, Ter Horst HJ, Keating P, Martijn A, Van Braeckel KN, Bos AF. Cerebral oxygenation in preterm infants with germinal matrix-intraventricular hemorrhages. Stroke. 2010;41(12):2901-7.

54. Pichler G, Cheung PY, Aziz K, Urlesberger B, Schmolzer GM. How to monitor the brain during immediate neonatal transition and resuscitation? A systematic qualitative review of the literature. Neonatology. 2014;105(3):205-10.

55. Sirc J, Dempsey EM, Miletin J. Cerebral tissue oxygenation index, cardiac output and superior vena cava flow in infants with birth weight less than 1250 grams in the first 48 hours of life. Early Hum Dev. 2013;89(7):44952.

56. Hyttel-Sorensen S, Pellicer A, Alderliesten T, Austin T, van Bel F, Benders M, et al. Cerebral near infrared spectroscopy oximetry in extremely preterm infants: phase II randomised clinical trial. BMJ. 2015;350:g7635.

57. Andersen CC, Karayil SM, Hodyl NA, Stark MJ. Early red cell transfusion favourably alters cerebral oxygen extraction in very preterm newborns. Arch Dis Child Fetal Neonatal Ed. 2015. 